\title{
Reconfigurable Microstrip Patch Antenna for Frequency Diversity Using RF MEMS
}

\author{
Younes Karfa Bekali ${ }^{1}$, Mohammed Essaaidi $^{2}$ \\ Department of Physics / Abdelmalek Essaadi University, Morocco"
}

\begin{abstract}
A novel reconfigurable patch antenna for frequency diversity is proposed by reconfiguring its geometry using tree rectangular tapes that are connected to the patch via six RF MEMS switches. So switching between the different frequency bands is achieved by using capacitive series RF-MEMS switches. The antenna was designed to operate at $2.6 \mathrm{GHz}, 3.1 \mathrm{GHz}, 3.5 \mathrm{GHz}$ and $5 \mathrm{GHz}$.
\end{abstract}

Keywords - Frequency diversity, Planar antenna, Reconfigurable antenna, RF MEMS, Switches

\section{INTRODUCTION}

With the tremendous advancement in communication technology followed by ever growing consumer demands the need for multi functional wireless communication devices is more than ever felt[1]. Reconfigurable antennas have recently received significant attention for their applications in communications, electronic surveillance and countermeasures [1].

In reconfigurable antennas, changing the shape of radiating element is achieved by switching [1]. The switching property allows the user to roam any existing network and have only a single handset to access a great number of services in [2].

A small, planar and reconfigurable microstrip patch antenna, suitable for many wireless communication applications such as $4 \mathrm{G}(2.6 \mathrm{GHz})$, WIMAX $(3.5 \mathrm{GHz})$ and $\mathrm{WiFi}(5 \mathrm{GHz})$ is presented in this letter. This antenna can operate easily at two frequencies depending on the state of the two switches. This antenna is obtained through a parametric study which optimizes and improves the result. Six switches MEMS are used to connect or disconnect a tree stapes to the patch antenna.

The MEMS play the role of a switch that is in the ON state or OFF state. The MEMS switches have been simulated by transmission lines for the "closed" state and for the "open" state the switches are simply removed. So in the OFF mode, the switch is removed from the simulation and the patch should be simulated with a complete slot. When the switch is $\mathrm{ON}$, it is modeled as a metal tape.

In this paper RF-MEMS switches is used for switching. It is also possible to use PIN diodes as switching element but we preferred MEMS switch for their significant better RF characteristics than conventional PIN diodes or FET switches and consumes less power Ref [3].

The proposed antenna design and performances are analyzed by using Ansoft High Frequency Structure Simulator (HFSS) [4].

\section{Antenna Design Procedure}

The geometry of proposed switchable printed patch antenna is shown in Figs. 1 and 2. It consists of a printed microstrip patch antenna on FR4_epoxy substrate of thickness $1.5 \mathrm{~mm}$ and a relative permittivity $\varepsilon \mathrm{r}=4.4$. The substrate has a length $\mathrm{L}=38 \mathrm{~mm}$ and a width $\mathrm{l}=20 \mathrm{~mm}$. The dimensions of the partial conducting ground plane are $20 \mathrm{~mm} \times 5.5 \mathrm{~mm}$.

The excitation is launched through a $50 \mathrm{Ohm}$ microstrip feed line, which has a width $\mathrm{w}=2.8 \mathrm{~mm}$. To achieve frequency diversity for the antenna, six switches are inserted between the patch antenna and tree rectangular tapes. The switches are being used to change the geometry of the antenna producing a reconfigurable antenna structure that offers more frequency agility. The dimensions of all parts of proposed antenna are presented in Table 1. To configurate the antenna, six switches are inserted close to the edge of the slot, which have a width $0.16 \mathrm{~mm}$ between the antenna and tapes.

Figures 3 and 4 shows a six switches and its configuration 


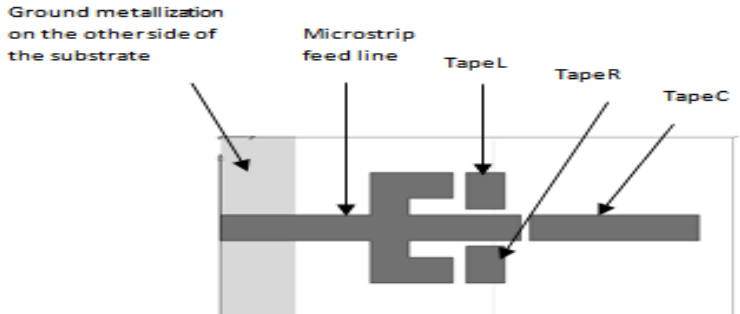

Fig. 1 Microstrip reconfigurable antenna on a 20 x $38(\mathrm{~mm})$ FR4 substrate

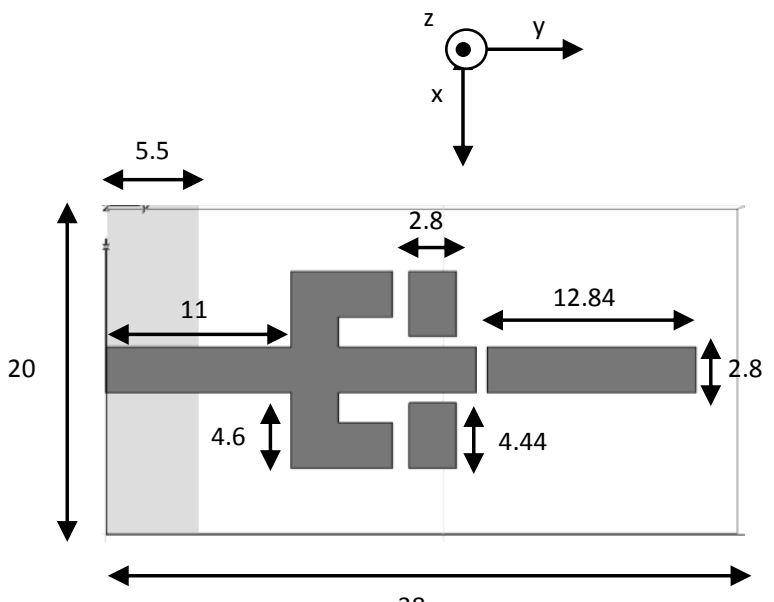

Fig. 2 All dimensions are in millimetres. The antenna is positioned in the $x-y$ plane.

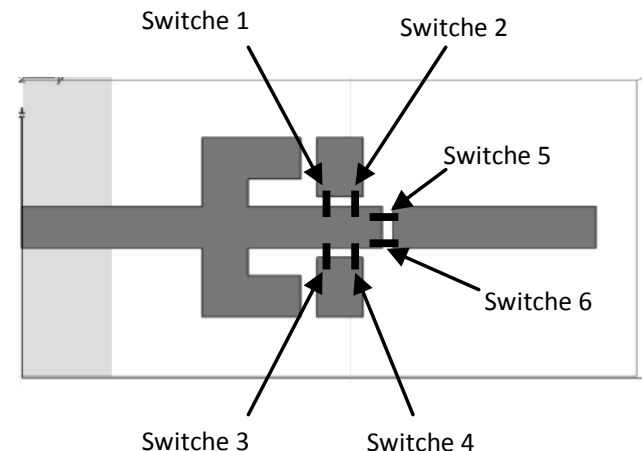

Fig. 3 Six switches are inserted between the patch antenna and tree rectangular tapes
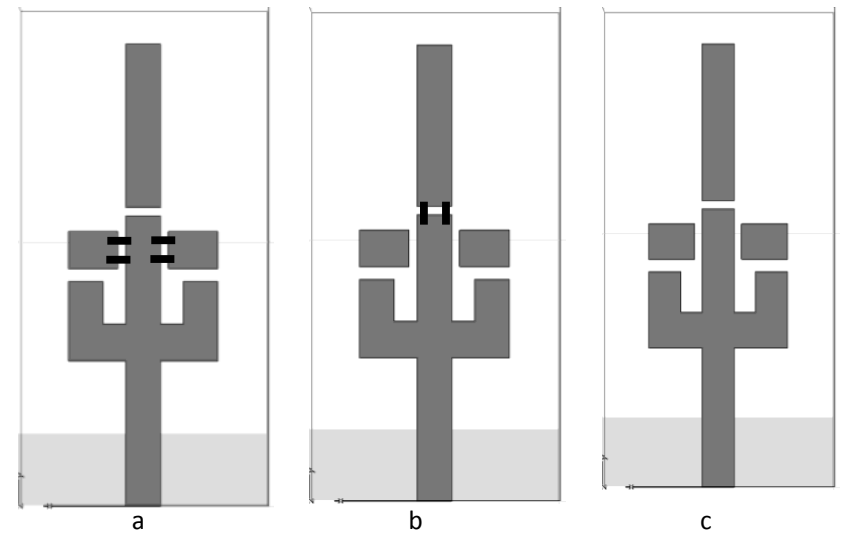

Fig. 4 The antenna configuration a) ON-ON-OFF b) OFF-OFF-ON c) OFF-OFF-OFF 


\section{ReSUlt AND DiscuSSION.}

Figures 5, 6, 7 shows the return loss for OFF-OFF-ON state, ON-ON-OFF state, and OFF-OFF-OFF state, simulated with HFSS. We can see that the antenna operate at four bands which covers the frequency band around $2.6 \mathrm{GHz}$ corresponding to $4 \mathrm{rd}$ generation $(4 \mathrm{G}$ ) for mobile communications, $5 \mathrm{GHz}$ (WiFi), $3.1 \mathrm{GHz}$, and $3.5 \mathrm{GHz}$ (WiMax). So the proposed antenna covers multiple standards and frequencies that are very useful for current and emerging wireless and mobile communication technologies, see figure 8 and table 1 .

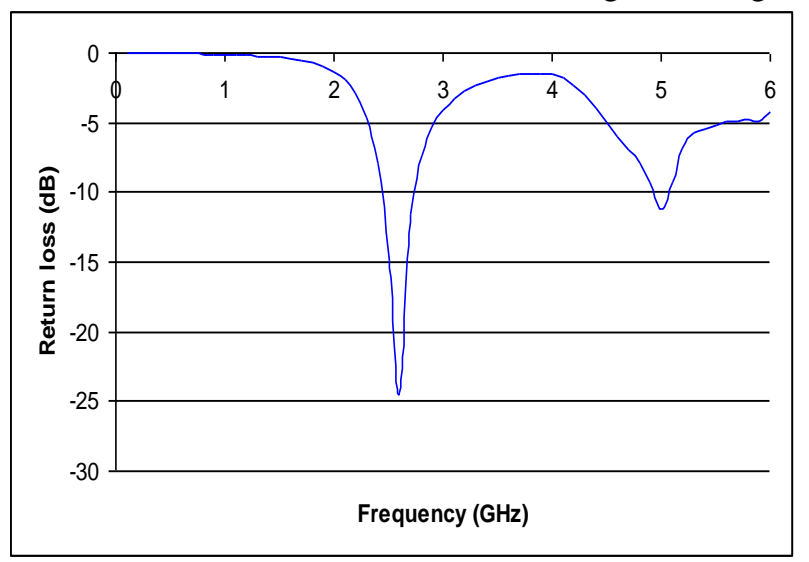

Fig. 5 Return loss for the OFF-OFF-ON state

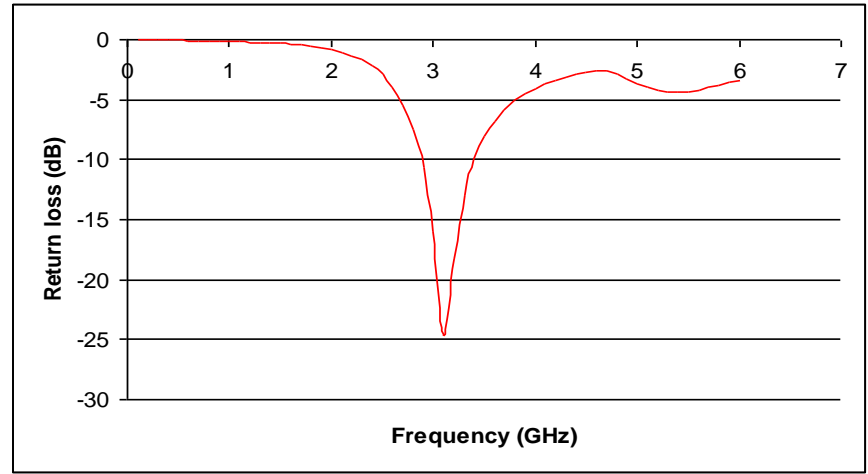

Fig. 6 Return loss for the ON-ON-OFF state

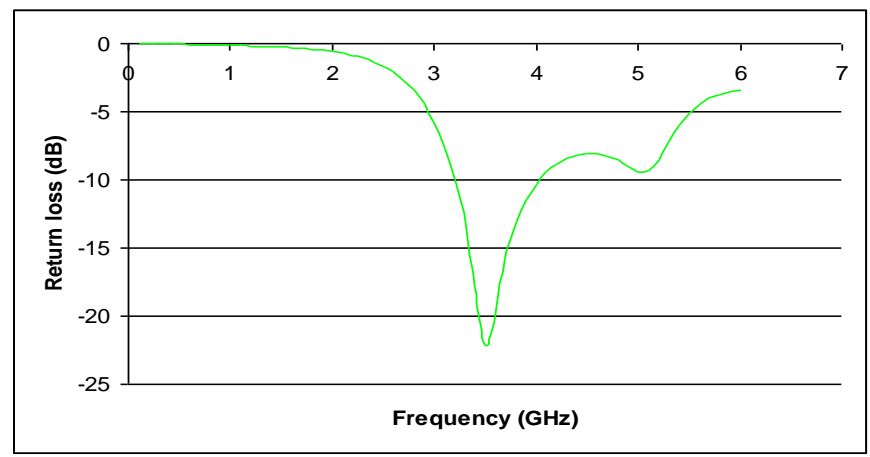

Fig. 7 Return loss for the OFF-OFF-OFF state 


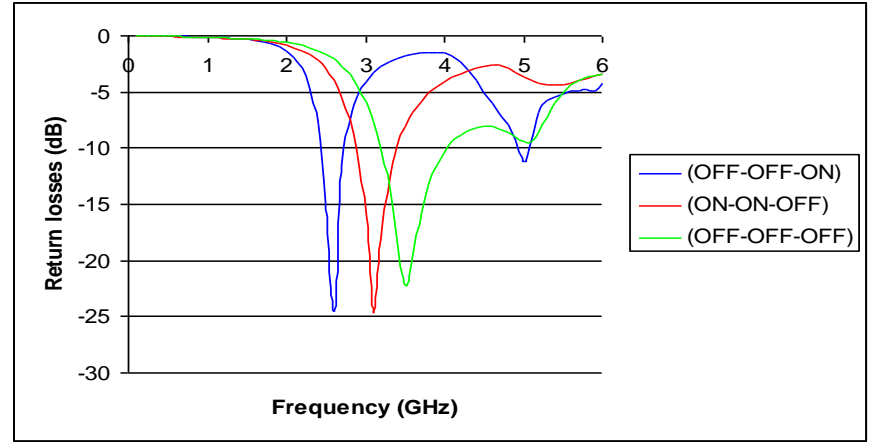

Fig. 8 Return losses for the all states

TABLE I Communication standards corresponding to the six switch configurations for the reconfigurable antenna

\begin{tabular}{|l|l|l|l|}
\hline $\begin{array}{l}\text { Switches 1 } \\
\text { And 2 }\end{array}$ & $\begin{array}{l}\text { Switches 3 } \\
\text { And 4 }\end{array}$ & $\begin{array}{l}\text { Switches 5 } \\
\text { And 6 }\end{array}$ & $\begin{array}{l}\text { Frequence } \\
\text { And } \\
\text { Stantard }\end{array}$ \\
\hline OFF & OFF & ON & $2.6 \mathrm{Ghz}(4 \mathrm{G})$ \\
\cline { 3 - 4 } & ON & OFF & $3.1 \mathrm{Ghz}(\mathrm{WiFi})$ \\
\hline ON & OFF & OFF & $\begin{array}{l}3.5 \mathrm{Ghz} \\
\text { (WiMax })\end{array}$ \\
\hline OFF & & & \multicolumn{2}{|}{} \\
\hline
\end{tabular}

\section{CONCLUSIONS}

A novel single feed microstrip antenna with reconfigurable frequency capability for frequency diversity applications has been proposed and discussed in this letter. Six switches are used to control the different resonance frequency of the proposed reconfigurable antenna. It is to be noted that the proposed antenna design is desirable for many wireless communication application such as WiFi, WiMax, and 4G.

\section{REFERENCES}

[1] Proceedings of the International Conference on Man-Machine Systems (ICoMMS)11 - 13 October 2009, Batu Ferringhi, Penang, MALAYSIA

[2] Behdad, N. and K. Sarabandi," A compact dual-multi-band wireless LAN antenna," IEEE Antennas and Propagation Society Internation Symposium, 2005 Vol. 2B, 527-30,.

[3] Shynu, S. V., G. Augustin, C. K. Aanandan, P. Mohanan, and K.Vasudevan, “A reconfigurable dual frequency slot loaded microstrip antenna controlled by pin-diodes", Microwave and Optical Technology Letters, 2005 Vol. 44, 374-376.

[4] Ansoft High Frequency Structure Simulator corporation, V 9.2, 2004, http://www.ansoft.com/hfss 